\title{
Proposta de atividades logísticas na Gestão da Cadeia de Suprimentos (SCM)
}

\author{
Márcia Maria Penteado Marchesinia*, Rosane Lúcia Chicarelli Alcântara ${ }^{b}$ \\ a*marcia.marchesini@ufabc.edu.br, UFABC, Brasil \\ brosane@dep.ufscar.br, UFSCar, Brasil
}

\section{Resumo}

A partir da Gestão da Cadeia De Suprimentos, a função logística expande seu escopo dentro da empresa e passa a exercer ou dar apoio à gestão e operação de diferentes processos chave de negócio. Os benefícios gerados pelo envolvimento da função logística em tais processos já foram amplamente discutidos na literatura, mas não foram identificadas as atividades que a logística deve executar em cada um dos processos para que esses benefícios sejam alcançados. 0 objetivo deste artigo foi propor atividades logísticas necessárias à operação eficiente e eficaz dos diferentes processos-chave de negócio da SCM. Este artigo é teórico-conceitual, de natureza exploratória e com abordagem da pesquisa qualitativa, utilizando o método de estudo multicaso e a entrevista pessoal por meio de um questionário semiestruturado. Constatou-se consistência das atividades logísticas propostas na realidade das empresas pesquisadas, sendo que a existência dessas atividades depende fortemente das características internas de cada empresa. Confirmou-se que, atualmente, a logística exerce suas atividades não mais com uma postura reativa e de forma isolada em sua área departamental ou funcional, mas sim com uma postura proativa dentro dos processos de negócio.

Palavras-chave

Gestão da Cadeia de Suprimentos (Supply Chain Management, SCM). Processos-chave de negócio. Escopo da gestão logística. Atividades logísticas.

\section{Introdução}

A partir do desenvolvimento do conceito de Gestão da Cadeia de Suprimentos (Supply Chain Management, $S C M$ ), a logística sofre modificações em seu escopo e prática e, através da gestão e operação do serviço logístico, passa a exercer influência direta na eficiência e eficácia dos processos-chave de negócio da SCM, ou seja, na habilidade de tais processos atenderem às necessidades dos clientes ao menor custo possível (HUTT; SPEH, 2001; BALLOU, 2001; MENTZER et al., 2001; STANK; DAVIS; FUGATE, 2005; BOWERSOX; CLOSS, 2001; WANKE, 2003; BOWERSOX; CLOSS; COOPER, 2006, 2007; LAMBERT; GARCÍA-DASTUGUE; CROXTON, 2008).

A atuação da logística deixa de se reduzir somente à esfera funcional ("silo ou área vertical"), passando a alcançar também a esfera horizontal dos processos-chave de negócio. Stank, Davis e Fugate (2005) afirmaram que a logistica possui natureza de estar presente além das fronteiras, o que implica os profissionais da área também estarem envolvidos em atividades e responsabilidades da cadeia de suprimentos.

Os benefícios gerados pelo envolvimento da função logística nos processos-chave de negócio da SCM já foram levantados por Lambert, García-Dastugue e Croxton (2008), mas não foram identificadas as atividades que a logística deve executar em cada um dos processos para que esses benefícios sejam alcançados. Outras fontes da literatura, tais como Christopher (1997), Ballou (2001), Kauffman (2002), Marchesini (2005) e Bowersox, Closs e Cooper (2007), também apontaram mudanças na função logística a partir da adoção da SCM, mas não as caracterizaram precisamente ou não discutiram as modificações no seu escopo dentro das empresas. 
Nesse sentido, há uma lacuna teórica sobre quais são as atividades logísticas que são desenvolvidas dentro dos diferentes processos-chave de negócio da SCM, gerando as duas proposições base deste artigo: P1 - A partir da difusão do conceito da SCM, ocorreram mudanças no escopo da função logística; P2 - Atividades logísticas passaram a fazer parte dos diferentes processos-chave de negócio da SCM, visando a melhoria do serviço logístico oferecido e a criação de valor para o cliente.

A questão de pesquisa que norteia este artigo é: Como ocorre o envolvimento da função logística nos processos-chave de negócio da SCM? Ou, mais detalhadamente: Dado que já são conhecidos na literatura os benefícios gerados pelo envolvimento da função logística nos processos-chave de negócio da SCM, quais são as atividades que a logística realiza dentro de tais processos? Essas atividades logísticas são válidas ou consistentes no ambiente empresarial?

Diante disso, o objetivo deste artigo é propor atividades logísticas necessárias à operação eficiente e eficaz dos diferentes processos-chave de negócio da SCM. Para atingir esse objetivo, a próxima seção apresenta os processos-chave de negócio da SCM. Na terceira seção é discutido o papel da função logística para a SCM em termos de benefícios trazidos pelo envolvimento da logística nesses processos. Na quarta seção são detalhados os aspectos metodológicos da pesquisa. Na quinta seção, propõem-se, atividades logísticas que são executadas dentro de tais processos, bem como o critério de sua classificação. A sexta seção expõe os resultados da validação de tais atividades logísticas no meio empresarial por meio de estudos de caso. Por fim, a sétima seção traz as discussões e considerações finais.

\section{A SCM: um conjunto de processos- chave de negócio}

Croxton et al. (2001) afirmam que cada vez mais a SCM vem sendo reconhecida como a gestão de processos-chave de negócio ao longo da rede de organizações que compõem a cadeia de suprimentos, sendo o processo de negócio um conjunto estruturado de atividades com os resultados de negócios voltados aos clientes. Para Mentzer et al. (2001), os processos são direcionados ao atendimento das necessidades dos clientes e caracterizam a forma como os produtos/ serviços se movimentam ao longo da cadeia de suprimentos e como a empresa está organizada.

Nesse sentido, Lambert, García-Dastugue e Croxton (2005) colocam que a SCM é implementada integrando funções corporativas, usando para tanto os processos de negócio dentro e entre empresas.
Considerando que um processo de negócio é um conjunto estruturado de atividades com resultados específicos para cada consumidor, modelos para a implantação da SCM devem descrever processos de forma detalhada, de maneira que eles possam ser implantados e posteriormente avaliados. Ainda de acordo com Lambert, García-Dastugue e Croxton (2005), apenas os modelos do Global Supply Chain Forum (GSCF) e o do Supply Chain Council (SCC) detalham suficientemente os processos, embora exista na literatura um total de cinco modelos de referência para a SCM. Os outros três modelos, publicados por Srivastava, Shervani e Fahey (1999), Bowersox, Closs e Stank (1999) e Mentzer (2001), são todos citados por Lambert, García-Dastugue e Croxton (2005), mas falham em ter um nível de detalhe suficiente para guiar a implementação da SCM nas empresas.

0 modelo do GSCF inclui todas as funções do negócio em cada um dos oito processos de gestão da cadeia de suprimentos, começando com a estratégia corporativa e ligando os aspectos operacionais do negócio à estratégia. Considera que os processoschave para integrar a cadeia de suprimentos são a gestão do relacionamento com o fornecedor e a gestão do relacionamento com o cliente. Esse modelo é orientado à gestão do relacionamento e suas métricas são relacionadas ao EVA (Economic Value Added).

Já o modelo do SCC, chamado de Supply Chain Operations Reference (SCOR), integra aspectos das funções de compras, operações e logística dentro dos seus cinco processos de gestão da cadeia de suprimentos (plan, source, make, deliver e return). Esse modelo não inclui funções como marketing, finanças e P\&D, o que torna sua aplicação mais direta, porém também o limita. O SCOR é focado mais na eficiência da transação do que no relacionamento entre clientes e fornecedores e suas métricas incluem dados de benchmarking que podem ser utilizados para melhorar a eficiência operacional.

Nesta pesquisa, considerou-se como base o modelo do GSCF por que:

- 0 modelo GSCF tem natureza mais acadêmica, tendo sido desenvolvido pelo Prof. Douglas M. Lambert e seu grupo de pesquisa (Ohio State University/USA), conjuntamente ao GSCF;

- Este artigo insere-se numa agenda de pesquisa voltada ao estudo do papel da logística no contexto da SCM, origanada no trabalho de Lambert, GarcíaDastugue e Croxton (2008), que também utilizaram o modelo GSCF;

- 0 modelo SCOR ainda está em formação, segundo Donadel et al. (2007);

- 0 modelo GSCF é mais completo, apresentando a análise e o detalhamento dos processos nos níveis 
estratégico e operacional, ao passo que o modelo SCOR é mais operacional (LAMBERT; GARCÍADASTUGUE; CROXTON, 2005; DONADEL et al., 2007). Como a logística é considerada atualmente área também estratégica, não limitando-se somente ao nível operacional de execução de fluxos de produtos e informações (BOWERSOX; CLOSS, 2001; FLEURY; WANKE, 2003; MARCHESINI, 2005), é mais pertinente o uso do modelo GSCF para a identificação da expansão do escopo da logística e sua atuação em todos os processos de negócio nos níveis estratégico, tático e operacional.

O GSCF identificou oito processos-chave que formam a base para o sucesso da cadeia de suprimentos. Esses oito processos-chave e suas características centrais são apresentados no Quadro 1.

\section{0 papel da logística na SCM}

Lambert, García-Dastugue e Croxton (2008) discutiram o papel da logística na empresa, identificando os benefícios trazidos à empresa pelo envolvimento da função logística em cada um dos oito processos-chave de negócio do modelo GSCF. Tais benefícios são divididos pelos autores, por um lado, em contribuições oferecidas pela logística à empresa e, por outro, em ganhos recebidos por esta função organizacional. Assume-se que tais ganhos são os motivadores da logística ou do envolvimento dos executivos da logística nos processos-chave de negócio, sendo benefícios gerados à própria função logística, ao passo que as contribuições são benefícios gerados pela logística a outras áreas, processos e/ ou toda empresa.

Os benefícios para a empresa advindos do envolvimento da logística nos oito processos bem como sua classificação pelos autores em termos de contribuição ou ganho são sumarizados no Quadro 2.

\section{Aspectos metodológicos}

Ressalta-se que os resultados apresentados neste artigo são parte de uma pesquisa maior. Miguel (2007) salienta que os aspectos metodológicos são o caminho selecionado e utilizado para responder à questão de pesquisa. De acordo com a abordagem desse autor, este artigo é de natureza teórico-conceitual, pois apresenta um conjunto teórico de atividades logísticas que podem ser executadas dentro dos processos-chave de negócio. É também uma pesquisa de natureza exploratória, dado que o tema - aumento do escopo da logística e detalhamento da inserção das suas atividades nos processos-chave de negócio da cadeia de suprimentos - é pouco explorado na literatura. A abordagem da pesquisa foi qualitativa, o método

Quadro 1. Características centrais dos processos-chave de negócio do modelo GSCF.

\begin{tabular}{|c|c|}
\hline Processos de negócio & Características centrais \\
\hline $\begin{array}{l}\text { 1. Gestão do relacionamento com } \\
\text { clientes (CRM) }\end{array}$ & $\begin{array}{l}\text { Estruturação da forma como os relacionamentos com os clientes são desenvolvidos e mantidos ao longo } \\
\text { do tempo, principalmente através da segmentação de clientes e da identificação dos clientes-chave e } \\
\text { da formulação de PSAs (Product and Service Agreements ou Acordos de Produtos e Serviços). PSAs são } \\
\text { documentos que representam o compromisso da empresa com o cliente, baseado em um entendimento } \\
\text { realista sobre as expectativas do cliente e as capacitações próprias da empresa e seus objetivos de } \\
\text { lucratividade. }\end{array}$ \\
\hline 2. Gestão do serviço ao cliente & $\begin{array}{l}\text { Representa o contato da empresa com o cliente, visando monitorar proativamente os PSAs e intervir } \\
\text { em nome do cliente quando necessário (quando ocorrem eventos como falhas, situações imprevistas, } \\
\text { modificações no pedido do cliente). }\end{array}$ \\
\hline 3. Gestão da demanda & $\begin{array}{l}\text { Realização do balanceamento entre as exigências dos clientes/demanda e a capacidade da cadeia de } \\
\text { suprimentos. Para tanto são necessários previsão de demanda, sincronização, redução da variabilidade da } \\
\text { demanda, aumento da flexibilidade da cadeia de suprimentos e desenvolvimento de planos de gestão de } \\
\text { contingências para potenciais interrupções no suprimento ou mudanças inesperadas na demanda. }\end{array}$ \\
\hline 4. Atendimento dos pedidos & $\begin{array}{l}\text { Envolve gerar, preencher e entregar pedidos dos clientes. Mas também as atividades necessárias } \\
\text { para definir as exigências dos clientes, projetar a rede e capacitar a empresa no atendimento dos } \\
\text { requerimentos dos clientes simultaneamente à minimização do custo total de entrega. }\end{array}$ \\
\hline $\begin{array}{l}\text { 5. Gestão do fluxo da } \\
\text { manufatura }\end{array}$ & $\begin{array}{l}\text { Compreende atividades necessárias à movimentação dos produtos através das plantas e à obtenção, } \\
\text { implementação e gestão da flexibilidade da manufatura ao longo da cadeia de suprimentos. A eficiência } \\
\text { do fluxo dos produtos através das plantas requer que as operações da empresa e as de seus fornecedores } \\
\text { sejam puxadas pela demanda dos consumidores finais. }\end{array}$ \\
\hline $\begin{array}{l}\text { 6. Gestão do relacionamento com } \\
\text { fornecedores }\end{array}$ & $\begin{array}{l}\text { É um processo "espelho" do CRM, ao estruturar a forma como os relacionamentos com fornecedores são } \\
\text { desenvolvidos e mantidos ao longo do tempo. Para tanto, são necessárias a segmentação de fornecedores, } \\
\text { a identificação dos fornecedores chave e a elaboração de PSAs com fornecedores. }\end{array}$ \\
\hline $\begin{array}{l}\text { 7. Desenvolvimento e } \\
\text { comercialização de produtos }\end{array}$ & $\begin{array}{l}\text { Provê a estrutura para desenvolver novos produtos e levá-los ao mercado, em um esforço conjunto com } \\
\text { clientes-chave e fornecedores-chave. }\end{array}$ \\
\hline 8. Gestão do retorno & $\begin{array}{l}\text { Processo de gestão efetiva do retorno de produtos. } 0 \text { processo está relacionado à logística reversa e } \\
\text { envolve a implementação de formas de evitar os retornos, o controle de entrada dos produtos retornados } \\
\text { e o desenvolvimento de orientações de conduta para os produtos retornados. }\end{array}$ \\
\hline
\end{tabular}

Fonte: adaptado de Lambert (2004, 2008a) e de Lambert, García-Dastugue e Croxton (2008). 
envolveu o estudo multicaso e a técnica para coleta dos dados consistiu na entrevista pessoal realizada por meio de um questionário semiestruturado. Conforme a abordagem de Ellram (1996), o design da pesquisa caracteriza-se como estudo empírico (dados reais) e análise predominantemente qualitativa, sendo os estudos de caso a técnica escolhida. Os estudos de caso são exploratórios e descritivos, uma vez que se busca

Quadro 2. 0 papel da logística em termos de benefícios trazidos à empresa.

\begin{tabular}{|c|c|c|}
\hline $\begin{array}{l}\text { Processo-chave de } \\
\text { negócio }\end{array}$ & Benefícios advindos do envolvimento da logística no processo & $\begin{array}{l}\text { Contribuição ou } \\
\text { ganho da logística }\end{array}$ \\
\hline \multirow{11}{*}{$\begin{array}{l}\text { 1. Gestão do } \\
\text { relacionamento com } \\
\text { clientes (CRM) }\end{array}$} & $\begin{array}{l}\text { Custos logísticos são capturados detalhadamente de forma a incluí-los no cálculo da lucratividade por cliente e } \\
\text { segmento de cliente }\end{array}$ & contribuição \\
\hline & 0 custo em servir é calculado para cada cliente-chave e segmento de cliente & contribuição \\
\hline & Capacitações logísticas são transformadas em entregas específicas & contribuição \\
\hline & Serviços logísticos são customizados com base na segmentação de clientes & contribuição \\
\hline & Serviços logísticos são incluídos nos PSAs (acordos de produtos e serviços) formais estabelecidos com clientes & contribuição \\
\hline & Profissionais da alta gestão entendem e utilizam as capacitações logisticas para competir & contribuição \\
\hline & Profissionais da alta gestão entendem as forças e as fraquezas logísticas dos competidores & contribuiç̧ão \\
\hline & Profissionais de gestão entendem como os serviços logísticos criam valor e vendem esse valor aos clientes & contribuição \\
\hline & Logística passa a influenciar nas soluções oferecidas para atender aos requerimentos dos clientes & ganho \\
\hline & Logística passa a influenciar no desenvolvimento de iniciativas colaborativas com clientes & ganho \\
\hline & Planejamento logístico é melhorado como resultado da diferenciação do serviço por segmentos de clientes & ganho \\
\hline \multirow{6}{*}{$\begin{array}{l}\text { 2. Gestão do } \\
\text { relacionamento com } \\
\text { fornecedores }\end{array}$} & $\begin{array}{l}\text { Custos logísticos são incluídos no cálculo do custo total de propriedade dos materiais comprados de forma a } \\
\text { avaliar, selecionar e segmentar fornecedores }\end{array}$ & contribuição \\
\hline & Considerações logísticas são incluídas nos PSAs dos fornecedores, considerando a sua segmentação & contribuição \\
\hline & $\begin{array}{l}\text { Custos logísticos são considerados quando se analisa o impacto dos requerimentos da empresa sobre a } \\
\text { lucratividade dos fornecedores }\end{array}$ & contribuição \\
\hline & $\begin{array}{l}\text { Logística de entrada é melhorada como resultado do entendimento das capacitações e operações logísticas dos } \\
\text { fornecedores }\end{array}$ & ganho \\
\hline & Logística pode influenciar o desenvolvimento de iniciativas de colaboração com fornecedores & ganho \\
\hline & $\begin{array}{l}\text { Custos da logística de entrada são reduzidos através da influência nas compras de serviços logísticos dos } \\
\text { fornecedores }\end{array}$ & ganho \\
\hline \multirow{4}{*}{$\begin{array}{l}\text { 3. Gestão do serviço } \\
\text { ao cliente }\end{array}$} & Potenciais falhas relacionadas à logistica podem ser detectadas e tratadas rapidamente & contribuição \\
\hline & Capacitações logísticas são usadas para recuperar potenciais falhas não causadas pela logística no serviço & contribuição \\
\hline & As causas raízes de falhas do serviço ao cliente relacionadas à logística são descobertas e estabelecidas & ganho \\
\hline & 0 desempenho da gestão do serviço ao cliente é medido sistematicamente e é relacionado às operações logísticas & contribuição \\
\hline \multirow{7}{*}{ 4. Gestão da demanda } & $\begin{array}{l}0 \text { processo de previsão da demanda ajusta-se bem às necessidades da função logística em termos informações } \\
\text { disponíveis no tempo adequado e nível de detalhe, incluindo horizonte de tempo, produto e geografia }\end{array}$ & contribuição \\
\hline & Decisões sobre iniciativas colaborativas (como Resposta Rápida, VMl e CPFR) são tomadas com inputs logisticos & contribuição \\
\hline & Atividades promocionais passaram a ser planejadas com inputs logísticos & ganho \\
\hline & 0 processo de sincronização inclui capacitações e informações logísticas & contribuição \\
\hline & Custos e implicações logísticas associados à variabilidade da demanda são entendidos pela organização & contribuição \\
\hline & As capacitações e os custos da flexibilidade baseada na logistica são entendidos pela organização & contribuição \\
\hline & Considerações logísticas são incluídas nos planos de gestão de contingências & contribuição \\
\hline \multirow{4}{*}{$\begin{array}{l}\text { 5. Atendimento dos } \\
\text { pedidos }\end{array}$} & Um conjunto mais completo de custos e questões logisticas é considerado para o projeto de redes globais & contribuição \\
\hline & $\begin{array}{l}0 \text { processo de atendimento do pedido é projetado de forma a satisfazer mais eficiente e eficazmente os } \\
\text { requerimentos dos clientes baseados na segmentação }\end{array}$ & contribuição \\
\hline & Recursos logísticos são alinhados com os requerimentos dos clientes & contribuição \\
\hline & $\begin{array}{l}\text { As tecnologias relacionadas à logística mais apropriada são usadas para suportar as tecnologias de atendimento } \\
\text { do pedido }\end{array}$ & contribuição \\
\hline \multirow{3}{*}{$\begin{array}{l}\text { 6. Gestão do fluxo da } \\
\text { manufatura }\end{array}$} & $\begin{array}{l}\text { Capacitações e custos logísticos são considerados na tomada de decisões relacionadas ao tempo de } \\
\text { atravessamento e flexibilidade da manufatura }\end{array}$ & contribuição \\
\hline & Alternativas para postergação são avaliadas considerando o impacto sobre os custos logísticos & contribuição \\
\hline & $\begin{array}{l}\text { Custos logísticos são considerados na avaliação das opções da manufatura para responder a eventos não } \\
\text { planejados }\end{array}$ & ganho \\
\hline \multirow{5}{*}{$\begin{array}{l}\text { 7. Desenvolvimento } \\
\text { e comercialização de } \\
\text { produtos }\end{array}$} & Custos logísticos são considerados no cálculo da lucratividade potencial dos novos produtos & contribuição \\
\hline & Capacitações e custos logísticos são considerados no projeto do novo produto & contribuição \\
\hline & Capacitações e custos logísticos são considerados na introdução e colocação dos novos produtos no mercado & contribuição \\
\hline & Custos logísticos são considerados na avaliação da proliferação de SKU & contribuição \\
\hline & Melhorias são realizadas nas operações logísticas para suportar os novos produtos & ganho \\
\hline \multirow{5}{*}{ 8. Gestão do retorno } & Capacitações logísticas são desenvolvidas considerando a rede logística reversa & contribuição \\
\hline & Retornos são avaliados de forma a identificar oportunidades de evitá-los nas operações logísticas & contribuição \\
\hline & $\begin{array}{l}\text { Orientações do controle de entrada de produtos são desenvolvidas para tornar eficiente o fluxo da logística } \\
\text { reversa }\end{array}$ & contribuição \\
\hline & $\begin{array}{l}\text { Custos logísticos são considerados na avaliação de opções de conduta (reciclagem, remanufatura ou uso por } \\
\text { mercados secundários) }\end{array}$ & contribuição \\
\hline & Logística influencia as decisões relacionadas ao fluxo dos bens reutilizáveis (pallets e containers) & contribuição \\
\hline
\end{tabular}

Fonte: baseado em Lambert, García-Dastugue e Croxton (2008). 
responder à questão de pesquisa elaborada na forma de "como" e "quais" (Como ocorre o envolvimento da função logística nos processos-chave de negócio da SCM? Quais são as atividades que a logística realiza dentro de tais processos?).

Yin (2001), Mollenkopf, Russo e Frankel (2007), Manuj e Mentzer (2008) e Thomas e Esper (2010) afirmaram que métodos qualitativos são considerados mais apropriados para fenômenos que são ainda pouco entendidos e explorados, como a SCM e o tema específico deste artigo. Para Godsell, Johnson e van Hoek (2010), a pesquisa qualitativa e o uso do método estudo de caso são os mais adequados em pesquisa sobre a SCM, pois ela é um tema que ainda se encontra em sua fase exploratória. Isso ocorre em função desse campo de conhecimento ser nascente, imaturo e de natureza altamente específica do contexto organizacional. Além de se enquadrar no tema da SCM, este artigo trata da área de logística, para a qual Davis e Mentzer (2006) consideram que a pesquisa qualitativa é a mais aceita e útil. Esses autores também indicam como desenho da pesquisa em logística o uso de entrevistas.

Ellram (1996) destaca que o uso da abordagem de estudo de caso requer projeto, execução e análise dos dados de forma apropriada, exigindo rigor metodológico e representação acurada dos dados empíricos. Nesse sentido, Miguel (2007) expôs que a realização dos estudos de caso não é uma tarefa trivial e elaborou uma proposta de conteúdo e sequência para a condução de um estudo de caso (Figura 1) que reflete os níveis táticos e operacionais da pesquisa (decisões relativas aos procedimentos de condução da pesquisa).
Com base nas etapas para a condução do estudo de caso elaborada por Miguel (2007) e no trabalho de Ellram (1996), as etapas gerais para o desenvolvimento desta pesquisa foram:

- Revisão teórica e delineamento das proposições da pesquisa;

- Elaboração do protocolo e do questionário da pesquisa;

- Seleção e contato com as empresas que seriam entrevistadas;

- Realização do teste piloto e ajustes do questionário;

- Realização dos estudos de caso;

- Análise dos casos, em que houve a transcrição das entrevistas, a construção de uma base de dados, estruturação e codificação dos dados coletados, busca por padrões de resultados;

- Elaboração de discussões e considerações finais.

Sobre a pesquisa de campo, as unidades de análise consistiram em empresas de grande porte de processamento de produtos alimentícios prontos para o consumo, sendo analisados seus processos-chave de negócio e sua função logística.

A seleção das três empresas foi feita por conveniência e teve caráter não probabilístico. Os critérios para escolha dos estudos de caso foram: a) empresas pertencentes ao elo de processamento da cadeia de suprimentos; b) empresas do setor alimentício; c) empresas que já adotaram o conceito da SCM e que têm processos de negócio em suas estruturas organizacionais. Para atender a esse último critério na escolha e conseguir a abertura e participação na pesquisa, inicialmente foram feitos contatos telefônicos com a área de logística das empresas, expondo os

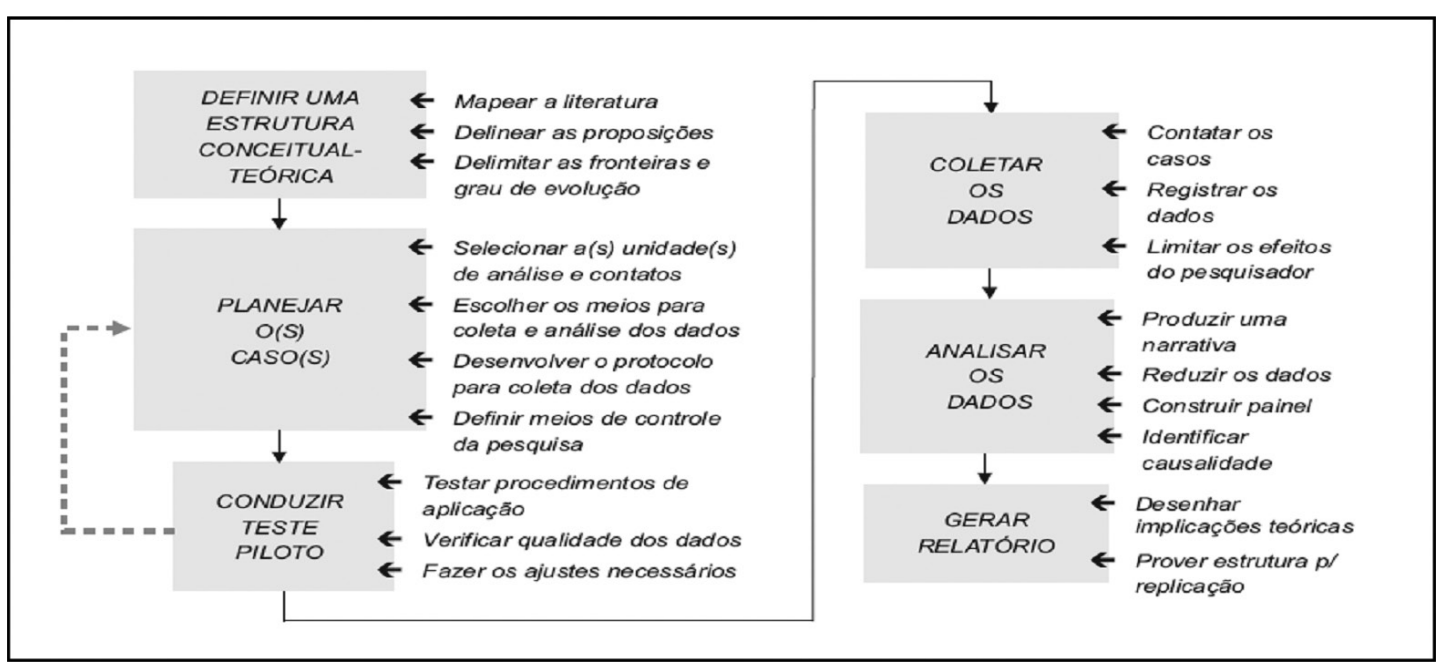

Figura 1. Sequência para condução do estudo de caso. Fonte: Miguel (2007). 
objetivos da pesquisa e verificando a sua adequação à finalidade. Em seguida, os contatos eram formalizados por e-mail, apresentando o protocolo e o questionário da pesquisa. Subsequentes contatos telefônicos e/ou por email para agendar as entrevistas foram realizados e as entrevistas foram feitas pessoalmente, no local definido pelos entrevistados. A realização completa das três entrevistas requereu cerca de oito meses, desde o final do primeiro semestre de 2010 até o mês de janeiro de 2011.

As entrevistas em cada empresa tiveram durações diferentes, sendo os cargos ocupados pelos entrevistados: Gerente de Customer Service e Distribuição (processo de logística) no caso da Empresa 1 (entrevista de duração de 5 horas); Gerente de Planejamento da Demanda para Alimentos no caso da Empresa 2 (2 horas); e Gerente de Logística e Supervisor de Logística (mercado Foods) no caso da Empresa 3 (4 horas).

0 questionário foi elaborado a partir da revisão teórica e envolveu três blocos:

- Bloco 1) Caracterização da empresa (por meio dos principais produtos que fabrica, do número de funcionários, do número de fábricas e $C D s$, do faturamento anual, do mercado que atende, dos principais clientes e dos principais concorrentes);

- Bloco 2) Implementação da SCM e da logística na estrutura organizacional da empresa;

- Bloco 3) Identificação das atividades logísticas que apoiam os diferentes processos de negócio existentes na empresa (avaliação pelo entrevistado da existência e da viabilidade de execução, na empresa, das atividades logísticas propostas, bem como a caracterização das atividades conforme critério previamente definido).

Para o tratamento dos dados coletados durante as entrevistas, utilizou-se a técnica de adequação ao padrão, em que se busca um padrão geral de resultados e se analisa o grau de adaptação desse padrão àquele anteriormente previsto (YIN, 2001). Assim, em contraponto entre teoria e prática, foram avaliadas a consistência das atividades logísticas e da forma de caracterização propostas, sendo os resultados apresentados e discutidos conforme a sequência de blocos do questionário. Utilizaram-se também os processos de codificação de dados abordados por Ellram (1996), em que os dados obtidos durante as entrevistas são fragmentados, examinados, comparados, categorizados e apresentados na forma de quadros, buscando-se "padrões de resultados", que são comparados com a teoria (padrões previstos), e definindo-se os "por quês" das convergências ou divergências entre esses padrões.

No Quadro 3, é apresentada uma síntese das características metodológicas deste artigo.

Nem todos os dados e informações obtidos foram apresentados para manter a confidencialidade prometida às empresas. Não houve a análise entre os casos, pois não se buscou verificar qual empresa estava mais desenvolvida em relação a outras, mas sim verificar a consistência das atividades logísticas propostas neste artigo.

\section{Proposição de atividades logísticas que podem ser executadas nos processos- chave de negócio da SCM}

Para que os benefícios identificados por Lambert, García-Dastugue e Croxton (2008) sejam alcançados, é necessário que a função logística realize diversas atividades cuja esfera de atuação não se limita somente à área funcional ou departamental isolada, mas alcança também os processos-chave de negócio

Quadro 3. Síntese dos aspectos metodológicos do artigo.

\begin{tabular}{|c|c|c|}
\hline \multicolumn{2}{|c|}{ Aspectos da pesquisa } & Descrição \\
\hline \multicolumn{2}{|c|}{ Abordagem da pesquisa } & Qualitativa \\
\hline \multicolumn{2}{|c|}{ Método de pesquisa } & Trabalho teórico-conceitual e estudos de casos exploratórios \\
\hline \multicolumn{2}{|c|}{ Objetivo geral da pesquisa } & Propor atividades logísticas necessárias à operação eficiente e eficaz dos processos-chave de negócio da SCM \\
\hline \multicolumn{2}{|c|}{ Questão de pesquisa } & Como ocorre o envolvimento da função logística nos processos-chave de negócio da SCM? \\
\hline \multirow{3}{*}{\multicolumn{2}{|c|}{ Unidades de análise }} & Empresas de processamento de produtos alimentícios de grande porte \\
\hline & & Processos-chave de negócio \\
\hline & & Função logística da empresa \\
\hline \multirow{3}{*}{\multicolumn{2}{|c|}{$\begin{array}{l}\text { Critérios para } \\
\text { escolha da amostra }\end{array}$}} & Empresas do elo de processamento da cadeia de suprimentos \\
\hline & & Empresas do setor alimentício \\
\hline & & Empresas que adotaram o conceito de SCM e têm processos de negócio em sua estrutura organizacional \\
\hline \multirow{2}{*}{ Coleta de dados } & Fontes & Entrevistas pessoais \\
\hline & Instrumento & Questionário semiestruturado \\
\hline \multirow{3}{*}{\multicolumn{2}{|c|}{ Forma de análise de resultados }} & Técnica de adequação ao padrão e codificação de dados, buscando o contraponto entre teoria e prática \\
\hline & & Análise intracasos \\
\hline & & Análise da consistência das atividades logísticas propostas na realidade das empresas pesquisadas \\
\hline
\end{tabular}

Fonte: elaborado pelas autoras. 
horizontais da SCM. Diante disso, este artigo propõe atividades logísticas a serem implementadas nos processos-chave de negócio para que tais benefícios possam ser alcançados.

0 levantamento dessas atividades logísticas foi feito tendo como base Lambert, García-Dastugue e Croxton (2008), Lambert (2004, 2008a, b, c), Bolumole, Knemeyer e Lambert (2003, 2008), Croxton (2002, 2008), Croxton et al. (2001, 2002, 2008), Goldsby e García-Dastugue (2003, 2008), Rogers, Lambert e Knemeyer $(2004,2008)$ e Rogers et al. (2002, 2008), que detalharam os subprocessos e atividades estratégicas e operacionais de cada um dos oito processos-chave de negócio do modelo GSCF. Em particular, a partir do trabalho de Lambert, García-Dastugue e Croxton (2008), foram focados os benefícios classificados como contribuições, uma vez que são benefícios gerados pela logística a outras áreas, processos e/ou toda empresa. Para que sejam realizadas uma ou mais contribuições, identificou-se uma atividade logística, com o intuito de chegar-se a um conjunto de atividades logísticas possivel de ser investigado nas empresas (de um total de 45 contribuições, chegou-se em 25 atividades logísticas teóricas).

Os Quadros 4 a 11 apresentam as atividades logísticas propostas, que podem ser implementadas em cada um dos oito processos-chave de negócio, a(s) contribuição(ões) que é(são) gerada(s) por cada uma delas e as referências utilizadas para a identificação de cada atividade logística.

Além da apresentação de tais atividades logísticas, propõe-se a caracterização a partir do critério de obrigatoriedade de sua existência nas empresas. Lambert, García-Dastugue e Croxton (2008) afirmaram que alguns dos papéis da logística dentro da SCM são padronizados dentro da logística e outros podem estar além da responsabilidade dessa área. Diante disso, este artigo assume que as atividades logísticas podem ser divididas em duas categorias: básicas/ obrigatórias (atividades obrigatoriamente presentes na função logística de qualquer empresa) ou opcionais/ não obrigatórias (atividades que a logística pode executar nos processos-chave de negócio de uma empresa, mas que não são obrigatórias).

Quadro 4. Atividades logísticas teóricas possíveis de serem implementadas no processo de CRM.

\begin{tabular}{|c|c|c|c|}
\hline \multicolumn{4}{|c|}{ Processo 1. Gestão do relacionamento com clientes (CRM) } \\
\hline $\begin{array}{c}\text { Contribuições à empresa advindas do envolvimento da } \\
\text { logística no processo }\end{array}$ & & Atividades logísticas propostas & Referências \\
\hline $\begin{array}{l}\text { Custos logísticos são capturados no nível de detalhe, de } \\
\text { forma a incluí-los no cálculo da lucratividade por cliente e } \\
\text { segmento de cliente }\end{array}$ & & \multirow{5}{*}{$\begin{array}{l}\text { Auxiliar na segmentação de clientes, provendo } \\
\text { informações sobre as capacitações e os custos } \\
\text { logísticos atuais }\end{array}$} & \multirow{8}{*}{$\begin{array}{l}\text { Lambert }(2004,2008 a, b) \\
\text { e Lambert, García- } \\
\text { Dastugue e Croxton (2008) }\end{array}$} \\
\hline $\begin{array}{l}0 \text { custo em servir é calculado para cada cliente-chave e } \\
\text { segmento de cliente }\end{array}$ & & & \\
\hline $\begin{array}{l}\text { Capacitações logísticas são transformadas em entregas } \\
\text { específicas }\end{array}$ & 1 & & \\
\hline $\begin{array}{l}\text { Serviços logísticos são customizados com base na } \\
\text { segmentação de clientes }\end{array}$ & & & \\
\hline $\begin{array}{l}\text { Serviços logísticos são incluídos nos PSAs formais } \\
\text { estabelecidos com clientes }\end{array}$ & & & \\
\hline $\begin{array}{l}\text { Profissionais da alta gestão entendem e utilizam as } \\
\text { capacitações logísticas para competir }\end{array}$ & \multirow{2}{*}{\multicolumn{2}{|c|}{$2 \begin{array}{l}\text { Prover a visão das capacitações logísticas } \\
\text { atuais e futuras para competir no mercado } \\
\text { e avaliar as forças e fraquezas logísticas dos } \\
\text { competidores }\end{array}$}} & \\
\hline $\begin{array}{l}\text { Profissionais da alta gestão entendem as forças e as } \\
\text { fraquezas logisticas dos competidores }\end{array}$ & & & \\
\hline $\begin{array}{l}\text { Profissionais de gestão entendem como os serviços } \\
\text { logísticos criam valor e vendem esse valor aos clientes }\end{array}$ & 3 & $\begin{array}{l}\text { ldentificar o valor criado pelo serviço logístico } \\
\text { para que seja oferecido e vendido aos clientes }\end{array}$ & \\
\hline
\end{tabular}

Fonte: elaborado pelas autoras.

Quadro 5. Atividades logísticas teóricas possíveis de serem implementadas no processo de gestão do relacionamento com fornecedores.

\begin{tabular}{|l|l|l|l|}
\hline \multicolumn{3}{|c|}{ Processo 2. Gestão do relacionamento com fornecedores } \\
\hline $\begin{array}{l}\text { Contribuições à empresa advindas do envolvimento da } \\
\text { logistica no processo }\end{array}$ & \multicolumn{2}{c|}{ Atividades logísticas propostas } \\
\hline $\begin{array}{l}\text { Custos logísticos são incluídos no cálculo do custo total de } \\
\text { propriedade dos materiais comprados, de forma a avaliar, } \\
\text { selecionar e segmentar fornecedores }\end{array}$ & 4 & $\begin{array}{l}\text { Auxiliar na avaliação, seleção e segmentação } \\
\text { de fornecedores, provendo o cálculo dos custos } \\
\text { logísticos de suprimento }\end{array}$ & $\begin{array}{l}\text { Lambert (2004, } \\
\text { 2008a, b) e } \\
\text { lambert, García- }\end{array}$ \\
\hline $\begin{array}{l}\text { Considerações logísticas são incluídas nos PSAs do } \\
\text { fornecedor, considerando a segmentação de fornecedores } \\
\text { Dastugue e Croxton } \\
\text { (2008) }\end{array}$ & 5 & $\begin{array}{l}\text { Definir as exigências logísticas impostas aos } \\
\text { fornecedores, em termos de serviço logístico a ser } \\
\text { prestado e de níveis de desempenho exigidos }\end{array}$ \\
\hline
\end{tabular}

Fonte: elaborado pelas autoras. 
Quadro 6. Atividades logísticas teóricas possíveis de serem implementadas no processo de gestão do serviço ao cliente.

\begin{tabular}{|c|c|c|c|}
\hline \multicolumn{4}{|c|}{ Processo 3. Gestão do serviço ao cliente } \\
\hline $\begin{array}{c}\text { Contribuições à empresa advindas do envolvimento da logística } \\
\text { no processo }\end{array}$ & & Atividades logisticas propostas & Referências \\
\hline $\begin{array}{l}\text { Potenciais falhas relacionadas à logística podem ser detectadas e } \\
\text { tratadas rapidamente }\end{array}$ & 6 & $\begin{array}{l}\text { Auxiliar no desenvolvimento de gatilhos e sinais que permitam } \\
\text { a detecção de falhas logísticas pelo grupo de gestão do } \\
\text { serviço ao cliente }\end{array}$ & \multirow{3}{*}{$\begin{array}{l}\text { Bolumole, Knemeyer e } \\
\text { Lambert }(2003,2008) \text {, } \\
\text { Lambert }(2004,2008 \text { a) } \\
\text { e Lambert, Garcia- } \\
\text { Dastugue e Croxton } \\
\text { (2008) }\end{array}$} \\
\hline $\begin{array}{l}\text { Capacitações logísticas são usadas para recuperar potenciais falhas } \\
\text { no serviço que não são causadas pela logística }\end{array}$ & 7 & $\begin{array}{l}\text { Auxiliar na recuperação de falhas do serviço ao cliente, sejam } \\
\text { elas de origem logistica ou não, fornecendo informações e } \\
\text { capacitações logísticas }\end{array}$ & \\
\hline $\begin{array}{l}\text { Potenciais falhas relacionadas à logística podem ser detectadas e } \\
\text { tratadas rapidamente }\end{array}$ & 8 & $\begin{array}{l}\text { Considerar as capacitações logísticas no projeto dos } \\
\text { procedimentos de resposta apropriada para cada evento } \\
\text { padronizado (falhas, mudanças) }\end{array}$ & \\
\hline
\end{tabular}

Fonte: elaborado pelas autoras.

Quadro 7. Atividades logísticas teóricas possíveis de serem implementadas no processo de gestão da demanda.

\begin{tabular}{|c|c|c|c|}
\hline \multicolumn{4}{|c|}{ Processo 4 . Gestão da demanda } \\
\hline $\begin{array}{l}\text { Contribuições à empresa advindas do envolvimento da logística } \\
\text { no processo }\end{array}$ & & Atividades logísticas propostas & Referências \\
\hline $\begin{array}{l}0 \text { processo de previsão da demanda ajusta-se bem às necessidades } \\
\text { da função logística em termos de tempo adequado e nivel de } \\
\text { detalhe, incluindo horizonte de tempo, produto e geografia }\end{array}$ & 9 & $\begin{array}{l}\text { Participar do projeto de previsão de demanda, de forma a gerar } \\
\text { informações adequadas às necessidades logísticas (informações } \\
\text { disponiveis no tempo adequado e com nivel de detalhamento }\end{array}$ & \multirow{6}{*}{$\begin{array}{l}\text { Croxton et al. (2002, } \\
\text { 2008), Lambert (2004, } \\
\text { 2008a) e Lambert, } \\
\text { García-Dastugue e } \\
\text { Croxton (2008) }\end{array}$} \\
\hline $\begin{array}{l}\text { Decisões sobre iniciativas colaborativas (como Resposta Rápida, } \\
\text { VMl e CPFR) são tomadas com inputs logísticos }\end{array}$ & & $\begin{array}{l}\text { relativo ao horizonte de tempo, produto e desagregação } \\
\text { geográfica) }\end{array}$ & \\
\hline $\begin{array}{l}0 \text { processo de sincronização inclui capacitações e informações } \\
\text { logisticas }\end{array}$ & 10 & $\begin{array}{l}\text { Fornecer informações sobre as restrições e capacitações } \\
\text { logisticas para a realização da sincronização entre operações e } \\
\text { demanda (Sales and Operations Planning, S\&OP) }\end{array}$ & \\
\hline $\begin{array}{l}\text { Custos e implicações logísticas associados à variabilidade da } \\
\text { demanda são entendidos pela organização }\end{array}$ & \multirow{2}{*}{11} & \multirow{2}{*}{$\begin{array}{l}\text { Auxiliar na análise dos custos e implicações logísticos advindos } \\
\text { da variabilidade da demanda e identificar formas para tornar os } \\
\text { sistemas logísticos mais flexíveis }\end{array}$} & \\
\hline $\begin{array}{l}\text { As capacitações e os custos da logística flexivel são entendidos } \\
\text { pela organização }\end{array}$ & & & \\
\hline $\begin{array}{l}\text { Considerações logísticas são incluídas nos planos de gestão de } \\
\text { contingências }\end{array}$ & 12 & $\begin{array}{l}\text { Auxiliar na gestão de contingências, identificando potenciais } \\
\text { interrupções logísticas à sincronização entre operações e } \\
\text { demanda e se envolvendo na solução mais efetiva de qualquer } \\
\text { interrupção }\end{array}$ & \\
\hline
\end{tabular}

Fonte: elaborado pelas autoras.

Quadro 8. Atividades logísticas teóricas possíveis de serem implementadas no processo de atendimento dos pedidos.

\begin{tabular}{|c|c|c|c|}
\hline \multicolumn{4}{|c|}{ Processo 5. Atendimento dos pedidos } \\
\hline $\begin{array}{l}\text { Contribuições à empresa advindas do envolvimento da logística } \\
\text { no processo }\end{array}$ & & Atividades logisticas propostas & Referências \\
\hline $\begin{array}{l}\text { Um conjunto mais completo de custos e questões logísticas é } \\
\text { considerado para o projeto de redes globais }\end{array}$ & 13 & $\begin{array}{l}\text { Auxiliar no projeto ou análise da rede, dispondo de um conjunto } \\
\text { mais completo de questões e de custos logísticos e verificando } \\
\text { se as capacitações e recursos logísticos atendem às necessidades } \\
\text { da empresa e seus clientes }\end{array}$ & \multirow{5}{*}{$\begin{array}{l}\text { Croxton et al. (2001), } \\
\text { Croxton (2002, 2008) } \\
\text { Lambert (2004, } \\
\text { 2008a) e Lambert, } \\
\text { Garcia-Dastugue e } \\
\text { Croxton (2008) }\end{array}$} \\
\hline $\begin{array}{l}\text { As tecnologias relacionadas à logística mais apropriadas são usadas } \\
\text { para suportar as tecnologias de atendimento do pedido }\end{array}$ & \multirow{3}{*}{14} & \multirow{3}{*}{$\begin{array}{l}\text { Auxiliar na avaliação das competências centrais (capacitações, } \\
\text { recursos e tecnologias) necessárias ao processo de atendimento } \\
\text { dos pedidos }\end{array}$} & \\
\hline $\begin{array}{l}\text { Recursos logísticos são alinhados com os requerimentos dos } \\
\text { clientes }\end{array}$ & & & \\
\hline $\begin{array}{l}0 \text { processo de atendimento do pedido é projetado de forma a } \\
\text { satisfazer mais eficiente e eficazmente os requerimentos dos } \\
\text { clientes baseados na segmentação }\end{array}$ & & & \\
\hline $\begin{array}{l}\text { No nivel operacional, o processo envolve atividades logisticas } \\
\text { tradicionais como o recebimento e a entrega de pedidos }\end{array}$ & 15 & $\begin{array}{l}\text { Operacionalizar o ciclo do pedido (receber, processar, preencher } \\
\text { e entregar o pedido) }\end{array}$ & \\
\hline
\end{tabular}

Fonte: elaborado pelas autoras.

Quadro 9. Atividades logísticas teóricas possíveis de serem implementadas no processo de gestão do fluxo de manufatura.

\begin{tabular}{|l|l|l|l|}
\hline \multicolumn{2}{|c|}{ Processo 6. Gestão do fluxo da manufatura } \\
\hline $\begin{array}{l}\text { Contribuições à empresa advindas do envolvimento da } \\
\text { logistica no processo }\end{array}$ & \multicolumn{3}{|c|}{ Atividades logísticas propostas } \\
\hline $\begin{array}{l}\text { Capacitações e custos logísticos são considerados } \\
\text { na tomada de decisões relacionadas ao tempo de } \\
\text { atravessamento e flexibilidade da manufatura }\end{array}$ & 16 & $\begin{array}{l}\text { Prover as capacitações logísticas e os custos necessários à } \\
\text { operacionalização do tempo adequado de atravessamento dos } \\
\text { produtos e à implantação do nível desejado de flexibilidade } \\
\text { da manufatura }\end{array}$ & $\begin{array}{l}\text { Goldsby e García-Dastugue } \\
\text { (2003, 2008), Lambert (2004, } \\
\text { 2008a) e Lambert, García- } \\
\text { Dastugue e Croxton (2008) }\end{array}$ \\
\hline $\begin{array}{l}\text { Alternativas para postergação são avaliadas considerando } \\
\text { o impacto sobre os custos logísticos }\end{array}$ & 17 & $\begin{array}{l}\text { Auxiliar na análise das alternativas de postergação por meio } \\
\text { da análise das capacitações e custos logísticos }\end{array}$ & \multicolumn{2}{|c|}{ Referências } \\
\hline
\end{tabular}

Fonte: elaborado pelas autoras. 
Quadro 10. Atividades logísticas teóricas possíveis de serem implementadas no processo de desenvolvimento e comercialização de produtos.

\begin{tabular}{|c|c|c|c|}
\hline \multicolumn{4}{|c|}{ Processo 7. Desenvolvimento e comercialização de produtos } \\
\hline $\begin{array}{l}\text { Contribuições à empresa advindas do envolvimento da } \\
\text { logística no processo }\end{array}$ & & Atividades logisticas propostas & Referências \\
\hline $\begin{array}{l}\text { Capacitações e custos logísticos são considerados no } \\
\text { projeto do novo produto }\end{array}$ & \multirow{4}{*}{18} & \multirow{4}{*}{$\begin{array}{l}\text { Contribuir na atividade de desenvolvimento de novos produtos, } \\
\text { com o conhecimento das restrições e capacitações logísticas. } \\
\text { Auxiliar na avaliação do impacto da proliferação de SKU para } \\
\text { garantir que a introdução dos novos produtos atenda aos } \\
\text { objetivos do negócio }\end{array}$} & \multirow{6}{*}{$\begin{array}{l}\text { Rogers, Lambert e Knemeyer } \\
\text { (2004, 2008), Lambert (2004, } \\
\text { 2008a) e Lambert, García- } \\
\text { Dastugue e Croxton (2008) }\end{array}$} \\
\hline $\begin{array}{l}\text { Capacitações e custos logísticos são considerados na } \\
\text { introdução e colocação dos novos produtos no mercado }\end{array}$ & & & \\
\hline $\begin{array}{l}\text { Melhorias são realizadas nas operações logísticas para } \\
\text { suportar os novos produtos }\end{array}$ & & & \\
\hline $\begin{array}{l}\text { Custos logísticos são considerados na avaliação da } \\
\text { proliferação de SKU }\end{array}$ & & & \\
\hline $\begin{array}{l}\text { Custos logísticos são considerados no cálculo da } \\
\text { lucratividade potencial dos novos produtos }\end{array}$ & 19 & $\begin{array}{l}\text { Auxiliar no cálculo da lucratividade potencial dos novos } \\
\text { produtos, provendo os custos logísticos associados ao } \\
\text { suprimento, manufatura e distribuição desses produtos }\end{array}$ & \\
\hline $\begin{array}{l}\text { Identificar as implicações logísticas (necessidades de } \\
\text { tempo e custo) associadas às alternativas de canais de } \\
\text { distribuição do novo produto }\end{array}$ & 20 & $\begin{array}{l}\text { Identificar as implicações logísticas (necessidades de tempo e } \\
\text { custo) associadas às alternativas de canais de distribuição do } \\
\text { novo produto }\end{array}$ & \\
\hline
\end{tabular}

Fonte: elaborado pelas autoras.

Quadro 11. Atividades logísticas teóricas possíveis de serem implementadas no processo de gestão do retorno.

\begin{tabular}{|c|c|c|c|}
\hline \multicolumn{4}{|c|}{ Processo 8. Gestão do retorno } \\
\hline Contribuições à empresa advindas do envolvimento da logística & & Atividades logísticas propostas & Referências \\
\hline $\begin{array}{l}\text { Capacitações logísticas são desenvolvidas considerando-se a rede } \\
\text { logística reversa }\end{array}$ & 21 & $\begin{array}{l}\text { Analisar e desenvolver a rede logística reversa, } \\
\text { desenvolvendo as capacitações logísticas necessárias }\end{array}$ & \multirow{6}{*}{$\begin{array}{l}\text { Rogers et al. (2002, 2008), } \\
\text { Lambert (2004, 2008a) e } \\
\text { Lambert, García-Dastugue } \\
\text { e Croxton (2008) }\end{array}$} \\
\hline $\begin{array}{l}\text { Retornos são avaliados de forma a identificar oportunidades de evitá- } \\
\text { los nas operações logísticas }\end{array}$ & 22 & $\begin{array}{l}\text { Auxiliar na identificação e implementação das } \\
\text { oportunidades de evitar os retornos }\end{array}$ & \\
\hline $\begin{array}{l}\text { Orientações do controle de entrada de produtos são desenvolvidas } \\
\text { para tornar eficiente o fluxo da logística reversa }\end{array}$ & \multirow{2}{*}{23} & \multirow{2}{*}{$\begin{array}{l}\text { Auxiliar no projeto e na execução do controle de } \\
\text { entrada de produtos, definindo os procedimentos para } \\
\text { atendimento dos pedidos e as rotas de coleta }\end{array}$} & \\
\hline $\begin{array}{l}\text { Logistica influencia as decisões relacionadas ao fluxo dos bens } \\
\text { reutilizáveis (pallets e containers) }\end{array}$ & & & \\
\hline $\begin{array}{l}\text { Custos logísticos são considerados na avaliação de opções de conduta } \\
\text { (reciclagem, remanufatura ou uso por mercados secundários) }\end{array}$ & 24 & $\begin{array}{l}\text { Auxiliar, com a informação dos custos logísticos, na } \\
\text { avaliação das opções de conduta da logística reversa } \\
\text { (reciclagem, remanufatura ou uso por mercados } \\
\text { secundários) }\end{array}$ & \\
\hline Não há & 25 & $\begin{array}{l}\text { Operacionalizar o ciclo de retorno (receber o pedido de } \\
\text { retorno, selecionar a conduta, determinar rota, receber } \\
\text { o retorno) }\end{array}$ & \\
\hline
\end{tabular}

Fonte: elaborado pelas autoras.

\section{Resultados dos estudos de caso}

0 objetivo dos estudos de caso foi verificar, no meio empresarial, a consistência das atividades logísticas teóricas nas empresas estudadas. $\mathrm{Na}$ primeira subseção serão apresentadas as empresas, detalhando como os processos de negócio e a função logística se caracterizam em cada uma delas. $\mathrm{Na}$ segunda subseção serão apresentados os resultados específicos para as atividades logísticas propostas por este artigo.

\subsection{Visão geral das três empresas: processos de negócio e função logística}

0 Quadro 12 permite a comparação entre as três empresas com base em suas características mais gerais.

A partir da estrutura organizacional geral da empresa e sua visão e implementação da logística e dos processos de negócio da SCM, pôde-se elaborar o
Quadro 13, que possibilita uma visão consolidada das três empresas estudadas com base em alguns fatores.

No Quadro 13 evidencia-se que muitos processoschave de negócio da SCM estão dentro do escopo da função logística nas três empresas pesquisas e, assim, são de responsabilidade direta dessa função.

\subsection{As atividades logísticas existentes nas empresas}

0 Quadro 14 expõe as atividades logísticas que existem nas três empresas. Especificamente, tal quadro apresenta se o entrevistado concorda ou não com a viabilidade de execução de cada atividade logística no ambiente empresarial, se a atividade existe na empresa em questão e registra a sua caracterização a partir do critério definido (básica ou opcional).

A partir dos dados coletados buscaram-se padrões possíveis e lógicos para as diversas combinações de respostas dos entrevistados, comparando-se com 
os padrões reais das respostas, como mostrado no Quadro 15. As combinações de respostas “não concorda-existe-básica ou opcional” foram descartadas, já que intuitivamente os entrevistados não declarariam que uma atividade da qual discordam existiria. Todos os entrevistados concordam com a viabilidade de existência no meio empresarial de todas as atividades logísticas propostas. Observa-se que a maior parte das respostas dos entrevistados consiste na combinação "concorda-existe-básica”. A maior parcela de respostas para a combinação "concorda-existeopcional" foi dada pelo entrevistado da Empresa 2. A combinação "concorda-não existe-básica” não foi encontrada nas respostas dos entrevistados, já que tal combinação demonstraria uma situação de fraqueza da função logística da empresa. Por fim, a combinação "concorda-não existe-opcional” reflete o total de atividades que inexistem em cada empresa.

$\mathrm{Na}$ Empresa 3 existem todas as 25 atividades logísticas. No caso da Empresa 1, dentro de um total de 25 atividades logísticas propostas inseridas nos processos-chave de negócio, a sua área de logística realiza 21 , sendo somente 4 inexistentes, a saber:
- Dentro do processo de CRM, não existem as atividades 2 e 3 . A atividade 2 inexiste em função do ponto específico relativo às forças e fraquezas logísticas dos concorrentes. 0 entrevistado afirmou que a Empresa 1 não possui acesso a essas informações, pois são sigilosas no mercado em geral, na medida em que todas as empresas, inclusive fornecedoras, devem respeitar a "carta de confidencialidade", em que se acorda sobre o sigilo das informações compartilhadas. Sobre a atividade 3, o entrevistado salientou que essa atividade existiria se a expressão "valor criado" fosse mudada para "exigência imposta". Isso porque uma vez estabelecido o relacionamento com o cliente e definidas as condições de atendimento, assumem-se compromissos, que se não cumpridos pela indústria geram multas impostas pelo cliente. lsso ocorre em função do atual contexto do mercado, em que o poder é detido pelo cliente varejista, seja ele de porte grande, médio, pequeno ou micro;

- Dentro do processo de gestão do fluxo de manufatura, não existem, as atividades 16 e 17. Estas inexistências se dão porque a fabricação/produção é considerada uma atividade fora da divisão de Supply Chain, sendo que esta divisão não interfere nas atividades de fabricação. Então, a função logística não atua

Quadro 12. Caracterização geral das empresas entrevistadas.

\begin{tabular}{|c|c|c|c|}
\hline Dimensão para comparação & Empresa 1 & Empresa 2 & Empresa 3 \\
\hline Setor & Bens de consumo & Bens de consumo & Bens de consumo \\
\hline Vendas (US\$ milhões) & $3.356,70$ & $4.684,10$ & $8.406,40$ \\
\hline Principais produtos & $\begin{array}{c}\text { Alimentos (achocolatados, leites, } \\
\text { chocolates, iogurtes, cafés, sorvetes, } \\
\text { temperos, sopas) }\end{array}$ & $\begin{array}{c}\text { Alimentos, higiene, limpeza e cuidados } \\
\text { pessoais (beleza) }\end{array}$ & $\begin{array}{c}\text { Alimentos, derivados de commodities } \\
\text { agrícolas (como soja), aço, negócios } \\
\text { imobiliários }\end{array}$ \\
\hline $\begin{array}{l}\text { Número de unidades industriais e CDs } \\
\text { no Brasil }\end{array}$ & 26 fábricas e 4 CDs & 10 fábricas e $7 \mathrm{CDs}$ & $\begin{array}{c}4 \text { fábricas e } 6 \text { CDs (para a unidade de } \\
\text { negócio Foods) }\end{array}$ \\
\hline
\end{tabular}

Fonte: entrevistas realizadas.

Quadro 13. SCM e logística nas três empresas: visão consolidada.

\begin{tabular}{|c|c|c|c|}
\hline Variáveis de análise & Empresa 1 & Empresa 2 & Empresa 3 \\
\hline Estrutura organizacional & $\begin{array}{l}\text { Matricial (áreas departamentais e } \\
\text { processos de negócio) }\end{array}$ & $\begin{array}{l}\text { Puramente horizontal (processos de } \\
\text { negócio), sendo a gestão dividida pelos } \\
\text { âmbitos das Américas e de cada país }\end{array}$ & $\begin{array}{c}\text { Convencional (áreas departamentais vistas } \\
\text { como processos de negócio) }\end{array}$ \\
\hline Modelo de SCM usado & $\begin{array}{c}\text { Mistura do modelo SCOR e modelo } \\
\text { próprio que enfatiza o serviço ao cliente }\end{array}$ & Modelo SCOR & Nenhum (experiência dos executivos) \\
\hline $\begin{array}{c}\text { Organização estratégica } \\
\text { da SCM }\end{array}$ & $\begin{array}{l}\text { Divisão de supply chain com seus } \\
\text { processos (inclusive há vice- } \\
\text {-presidente de supply chain) }\end{array}$ & Processo de cadeia de suprimentos & Não há um processo ou área de SCM \\
\hline $\begin{array}{l}\text { Processos-chave de negócio } \\
\text { existentes }\end{array}$ & $\begin{array}{l}\text { Dentro da divisão de supply chain, há } \\
\text { quatro processos (Demand and Supply } \\
\text { Planning - DSP, Compras, Comércio } \\
\text { Exterior e Customer Service e Distribuição) }\end{array}$ & $\begin{array}{l}\text { Quatro processos de negócio: Cadeia } \\
\text { de suprimentos, Marketing, Finanças e } \\
\text { Recursos Humanos. O processo da Cadeia } \\
\text { de suprimentos possui } 6 \text { subprocessos: } \\
\text { Suprimentos, Planejamento estratégico, } \\
\text { Produção (PCP), S\&OP (Sales and } \\
\text { Operations Planning), Distribuição } \\
\text { (armazenagem e transporte) e Gestão do } \\
\text { serviço logístico }\end{array}$ & $\begin{array}{c}\text { Nove processos-chave: marketing, vendas, } \\
\text { compras, } \mathrm{Tl} \text {, logística, desenvolvimento, } \\
\text { planejamento do negócio, manufatura e } \\
\text { controladoria }\end{array}$ \\
\hline Função logística na empresa & $\begin{array}{l}\text { Processo de “Customer service } \\
\text { e distribuição" (subprocessos de } \\
\text { CRM, Gestão do serviço ao cliente e } \\
\text { Atendimento do pedido) }\end{array}$ & $\begin{array}{l}\text { Quatro subprocessos: Suprimentos, } \\
\text { PCP (apoio à produção), Distribuição } \\
\text { (armazenagem e transporte) e Gestão de } \\
\text { serviços logísticos }\end{array}$ & $\begin{array}{l}\text { Processo de logistica. Oito subprocessos: } \\
\text { Serviço ao cliente (a logística reversa está } \\
\text { dentro desse subprocesso); Alocação/ } \\
\text { rotação; Transporte; Armazéns; } \\
\text { Desenvolvimento de processos logísticos; } \\
\text { PCP (inbound e outbound produtivos) }\end{array}$ \\
\hline $\begin{array}{l}\text { Relação da função logística } \\
\text { com os oito processos } \\
\text { teóricos do modelo GSCF }\end{array}$ & $\begin{array}{c}\text { A função logística abrange quatro } \\
\text { processos teóricos (CRM, Gestão do } \\
\text { serviço ao cliente, Atendimento de pedidos } \\
\text { e Gestão do retorno) }\end{array}$ & $\begin{array}{l}\text { A função logística abrange cinco } \\
\text { processos teóricos (CRM, Gestão do } \\
\text { serviço ao cliente, Atendimento de } \\
\text { pedidos, Gestão do relacionamento com } \\
\text { fornecedores e Gestão do retorno) }\end{array}$ & $\begin{array}{l}\text { A função logística abrange cinco } \\
\text { processos teóricos (Gestão do serviço ao } \\
\text { cliente, Gestão da demanda, Atendimento } \\
\text { de pedidos, Gestão do fluxo de } \\
\text { manufatura e Gestão do retorno) }\end{array}$ \\
\hline
\end{tabular}

Fonte: entrevistas realizadas. 
Quadro 14. Atividades logísticas nas empresas analisadas.

\begin{tabular}{|c|c|c|c|c|c|}
\hline \multicolumn{2}{|r|}{ Atividades logisticas } & Empresa & $\begin{array}{c}\text { Concorda (C) } \\
\text { ou não (N) }\end{array}$ & $\begin{array}{l}\text { Existe ou } \\
\text { não }\end{array}$ & $\begin{array}{l}\text { Básica ou } \\
\text { opcional }\end{array}$ \\
\hline \multicolumn{6}{|c|}{ Processo 1. Gestão do relacionamento com clientes (CRM) } \\
\hline \multirow{3}{*}{1} & \multirow{3}{*}{$\begin{array}{l}\text { Auxiliar na segmentação de clientes, provendo informações sobre as atuais } \\
\text { capacitações e custos logísticos }\end{array}$} & 1 & $\mathrm{C}$ & Sim & Básica \\
\hline & & 2 & $\mathrm{C}$ & Sim & Básica \\
\hline & & 3 & C & Sim & Básica \\
\hline \multirow{3}{*}{2} & \multirow{3}{*}{$\begin{array}{l}\text { Prover a logística como forma de competição no mercado, oferecendo a visão das } \\
\text { capacitações logísticas atuais e futuras e avaliando as forças e fraquezas logísticas } \\
\text { dos competidores }\end{array}$} & 1 & $\mathrm{C}$ & Não & Opcional \\
\hline & & 2 & C & Sim & Opcional \\
\hline & & 3 & $\mathrm{C}$ & Sim & Básica \\
\hline \multirow{3}{*}{3} & \multirow{3}{*}{$\begin{array}{l}\text { Identificar o valor criado pelo serviço logístico, a ser oferecido e vendido aos } \\
\text { clientes }\end{array}$} & 1 & $\mathrm{C}$ & Não & Opcional \\
\hline & & 2 & $\mathrm{C}$ & Sim & Opcional \\
\hline & & 3 & C & Sim & Básica \\
\hline \multicolumn{6}{|c|}{ Processo 2. Gestão do relacionamento com fornecedores } \\
\hline \multirow{3}{*}{4} & \multirow{3}{*}{$\begin{array}{l}\text { Auxiliar na avaliação, seleção e segmentação de fornecedores, provendo o cálculo } \\
\text { dos custos logísticos de suprimentos }\end{array}$} & 1 & $\mathrm{C}$ & Sim & Básica \\
\hline & & 2 & $\mathrm{C}$ & Sim & Básica \\
\hline & & 3 & $\mathrm{C}$ & Sim & Básica \\
\hline \multirow{3}{*}{5} & \multirow{3}{*}{$\begin{array}{l}\text { Definir as exigências logísticas impostas aos fornecedores, em termos de serviço } \\
\text { logístico a ser prestado e de níveis de desempenho exigidos }\end{array}$} & 1 & C & Sim & Básica \\
\hline & & 2 & $\mathrm{C}$ & Sim & Opcional \\
\hline & & 3 & C & $\operatorname{Sim}$ & Básica \\
\hline \multicolumn{6}{|c|}{ Processo 3. Gestão do serviço ao cliente } \\
\hline \multirow{3}{*}{6} & \multirow{3}{*}{$\begin{array}{l}\text { Auxiliar no desenvolvimento de gatilhos e sinais que permitam a deteç̧ão de } \\
\text { falhas logisticas pelo grupo de gestão do serviço ao cliente }\end{array}$} & 1 & $\mathrm{C}$ & Sim & Opcional \\
\hline & & 2 & $\mathrm{C}$ & Sim & Opcional \\
\hline & & 3 & $\mathrm{C}$ & Sim & Básica \\
\hline \multirow{3}{*}{7} & \multirow{3}{*}{$\begin{array}{l}\text { Auxiliar na recuperação de falhas do serviço ao cliente, sejam elas de origem } \\
\text { logística ou não, fornecendo informações e capacitações logísticas }\end{array}$} & 1 & $\mathrm{C}$ & Sim & Opcional \\
\hline & & 2 & $\mathrm{C}$ & Sim & Opcional \\
\hline & & 3 & $\mathrm{C}$ & Sim & Básica \\
\hline \multirow{3}{*}{8} & \multirow{3}{*}{$\begin{array}{l}\text { Considerar as capacitações logísticas no projeto dos procedimentos de resposta } \\
\text { apropriada para cada evento padronizado (falhas, mudanças) }\end{array}$} & 1 & $\mathrm{C}$ & Sim & Básica \\
\hline & & 2 & C & Sim & Opcional \\
\hline & & 3 & C & Sim & Básica \\
\hline \multicolumn{6}{|c|}{ Processo 4. Gestão da demanda } \\
\hline & Participar do projeto de previsão de demanda, de forma a gerar informações & 1 & $\mathrm{C}$ & $\operatorname{Sim}$ & Básica \\
\hline 9 & adequadas às necessidades logísticas (informações disponiveis no tempo & 2 & $\mathrm{C}$ & Sim & Básica \\
\hline & desagregação geográfica) & 3 & C & Sim & Básica \\
\hline & Fornecer informações sobre as restrições e capacitações logísticas para a & 1 & C & Sim & Básica \\
\hline 10 & realização da sincronização entre operações e demanda (Sales and Operations & 2 & $\mathrm{C}$ & Sim & Básica \\
\hline & Planning - S\&OP) & 3 & $\mathrm{C}$ & Sim & Básica \\
\hline & & 1 & $\mathrm{C}$ & Sim & Básica \\
\hline 11 & Auxiliar na análise dos custos e implicações logísticos advindos da variabilidade da & 2 & $\mathrm{C}$ & Não & Opcional \\
\hline & & 3 & C & Sim & Básica \\
\hline & Auxiliar na gestão de contingências, identificando potenciais interrupções & 1 & C & Sim & Básica \\
\hline 12 & logísticas à sincronização entre operações e demanda e envolvendo-se na solução & 2 & $\mathrm{C}$ & Sim & Opcional \\
\hline & mais efetiva a qualquer interrupção & 3 & $\mathrm{C}$ & Sim & Básica \\
\hline & Processo 5. Atendimento dos pedidos & & & & \\
\hline & Auxiliar no projeto ou análise da rede, dispondo de um conjunto mais completo de & 1 & C & $\operatorname{Sim}$ & Básica \\
\hline 13 & questões e custos logísticos e verificando se as capacitações e recursos logísticos & 2 & $\mathrm{C}$ & Sim & Básica \\
\hline & atendem às necessidades da empresa e de seus clientes & 3 & C & Sim & Básica \\
\hline & & 1 & $\mathrm{C}$ & Sim & Básica \\
\hline 14 & Auxiliar na avaliação das competências centrais (capacitações, recursos e & 2 & C & Sim & Opcional \\
\hline & & 3 & C & Sim & Básica \\
\hline & & 1 & $\mathrm{C}$ & Sim & Básica \\
\hline 15 & $\begin{array}{l}\text { Operacionalizar o ciclo do pedido (receber, processar, preencher e entregar o } \\
\text { pedido) }\end{array}$ & 2 & $\mathrm{C}$ & Sim & Básica \\
\hline & & 3 & C & Sim & Básica \\
\hline
\end{tabular}


Quadro 14. Continuação...

\begin{tabular}{|c|c|c|c|c|c|}
\hline \multicolumn{2}{|r|}{ Atividades logísticas } & Empresa & $\begin{array}{l}\text { Concorda }(\mathrm{C}) \\
\text { ou não }(\mathrm{N})\end{array}$ & $\begin{array}{l}\text { Existe ou } \\
\text { não }\end{array}$ & $\begin{array}{c}\text { Básica ou } \\
\text { opcional }\end{array}$ \\
\hline \multicolumn{6}{|c|}{ Processo 6. Gestão do fluxo da manufatura } \\
\hline \multirow{3}{*}{16} & \multirow{3}{*}{$\begin{array}{l}\text { Prover as capacitações logísticas e os custos necessários à operacionalização } \\
\text { do tempo adequado de atravessamento dos produtos e à implantação do nível } \\
\text { desejado de flexibilidade da manufatura }\end{array}$} & 1 & C & Não & Opcional \\
\hline & & 2 & C & Sim & Opcional \\
\hline & & 3 & C & Sim & Básica \\
\hline \multirow{3}{*}{17} & \multirow{3}{*}{$\begin{array}{l}\text { Auxiliar na análise das alternativas de postergação por meio da análise das } \\
\text { capacitações e custos logísticos }\end{array}$} & 1 & C & Não & Opcional \\
\hline & & 2 & C & $\operatorname{Sim}$ & Básica \\
\hline & & 3 & C & Sim & Básica \\
\hline \multicolumn{6}{|c|}{ Processo 7. Desenvolvimento e comercialização de produtos } \\
\hline \multirow{3}{*}{18} & \multirow{3}{*}{$\begin{array}{l}\text { Contribuir na atividade de desenvolvimento de novos produtos, com o } \\
\text { conhecimento das restrições e capacitações logísticas, e auxiliar na avaliação } \\
\text { do impacto da proliferação de SKU, para garantir que a introdução dos novos } \\
\text { produtos atenda aos objetivos do negócio }\end{array}$} & 1 & C & Sim & Básica \\
\hline & & 2 & C & Sim & Opcional \\
\hline & & 3 & C & $\mathrm{Sim}$ & Básica \\
\hline \multirow{3}{*}{19} & \multirow{3}{*}{$\begin{array}{l}\text { Auxiliar no cálculo da lucratividade potencial dos novos produtos, provendo os } \\
\text { custos logísticos associados ao suprimento, manufatura e distribuição desses } \\
\text { produtos }\end{array}$} & 1 & $\mathrm{C}$ & Sim & Básica \\
\hline & & 2 & C & Sim & Básica \\
\hline & & 3 & C & Sim & Básica \\
\hline \multirow{3}{*}{20} & \multirow{3}{*}{$\begin{array}{l}\text { Identificar as implicações logísticas (necessidades de tempo e custo) associadas às } \\
\text { alternativas de canais de distribuição do novo produto }\end{array}$} & 1 & C & $\operatorname{Sim}$ & Básica \\
\hline & & 2 & C & Sim & Opcional \\
\hline & & 3 & C & Sim & Básica \\
\hline \multicolumn{6}{|c|}{ Processo 8. Gestão do retorno } \\
\hline \multirow{3}{*}{21} & \multirow{3}{*}{$\begin{array}{l}\text { Analisar e desenvolver a rede logística reversa, desenvolvendo as capacitações } \\
\text { logísticas necessárias }\end{array}$} & 1 & $\mathrm{C}$ & Sim & Básica \\
\hline & & 2 & $\mathrm{C}$ & Sim & Opcional \\
\hline & & 3 & C & Sim & Básica \\
\hline \multirow{3}{*}{22} & \multirow{3}{*}{ Auxiliar na identificação e implementação das oportunidades de evitar os retornos } & 1 & C & Sim & Básica \\
\hline & & 2 & C & Sim & Básica \\
\hline & & 3 & $\mathrm{C}$ & Sim & Básica \\
\hline \multirow{3}{*}{23} & \multirow{3}{*}{$\begin{array}{l}\text { Auxiliar no projeto e na execução do controle de entrada de produtos, definindo } \\
\text { os procedimentos para atendimento dos pedidos e as rotas de coleta }\end{array}$} & 1 & C & Sim & Básica \\
\hline & & 2 & C & Sim & Básica \\
\hline & & 3 & C & Sim & Básica \\
\hline \multirow{3}{*}{24} & \multirow{3}{*}{$\begin{array}{l}\text { Auxiliar, com a informação dos custos logísticos, na avaliação das opções de } \\
\text { conduta da logística reversa (reciclagem, remanufatura ou uso por mercados } \\
\text { secundários) }\end{array}$} & 1 & C & Sim & Básica \\
\hline & & 2 & $\mathrm{C}$ & Não & Opcional \\
\hline & & 3 & $\mathrm{C}$ & Sim & Básica \\
\hline \multirow{3}{*}{25} & \multirow{3}{*}{$\begin{array}{l}\text { Operacionalizar o ciclo de retorno (receber o pedido de retorno, selecionar a } \\
\text { conduta, determinar rota, receber o retorno) }\end{array}$} & 1 & C & Sim & Básica \\
\hline & & 2 & $\mathrm{C}$ & Sim & Básica \\
\hline & & 3 & $\mathrm{C}$ & Sim & Básica \\
\hline
\end{tabular}

Fonte: entrevistas realizadas.

Quadro 15. Análise dos dados coletados: verificação das várias combinações possíveis e lógicas para as respostas dos entrevistados.

\begin{tabular}{|c|c|c|c|c|c|c|c|}
\hline & $\begin{array}{l}\text { Concorda } \\
\text { ou não }\end{array}$ & $\begin{array}{l}\text { Existe ou } \\
\text { não }\end{array}$ & $\begin{array}{l}\text { Básica ou } \\
\text { opcional }\end{array}$ & Empresa & $\begin{array}{l}\text { Número de } \\
\text { respostas }\end{array}$ & $\begin{array}{l}\text { Total do } \\
\text { número de } \\
\text { respostas }\end{array}$ & $\begin{array}{l}\text { Porcentagem: número de } \\
\text { respostas/total de respostas dos } \\
\text { três entrevistados (75) }\end{array}$ \\
\hline \multirow{15}{*}{$\begin{array}{l}\text { Combinações } \\
\text { possíveis e } \\
\text { lógicas }\end{array}$} & \multirow{3}{*}{$\begin{array}{c}\text { Não } \\
\text { concorda }\end{array}$} & \multirow{3}{*}{ Não existe } & \multirow{3}{*}{ Opcional } & 1 & 0 & \multirow{3}{*}{0} & \multirow{3}{*}{$0 \%$} \\
\hline & & & & 2 & 0 & & \\
\hline & & & & 3 & 0 & & \\
\hline & \multirow{3}{*}{ Concorda } & \multirow{3}{*}{ Existe } & \multirow{3}{*}{ Básica } & 1 & 19 & \multirow{3}{*}{55} & \multirow{3}{*}{$73,3 \%$} \\
\hline & & & & 2 & 11 & & \\
\hline & & & & 3 & 25 & & \\
\hline & \multirow{3}{*}{ Concorda } & \multirow{3}{*}{ Existe } & \multirow{3}{*}{ Opcional } & 1 & 2 & \multirow{3}{*}{14} & \multirow{3}{*}{$18,7 \%$} \\
\hline & & & & 2 & 12 & & \\
\hline & & & & 3 & 0 & & \\
\hline & \multirow{3}{*}{ Concorda } & \multirow{3}{*}{ Não existe } & \multirow{3}{*}{ Básica } & 1 & 0 & \multirow{3}{*}{0} & \multirow{3}{*}{$0 \%$} \\
\hline & & & & 2 & 0 & & \\
\hline & & & & 3 & 0 & & \\
\hline & \multirow{3}{*}{ Concorda } & \multirow{3}{*}{ Não existe } & \multirow{3}{*}{ Opcional } & 1 & 4 & \multirow{3}{*}{6} & \multirow{3}{*}{$8,0 \%$} \\
\hline & & & & 2 & 2 & & \\
\hline & & & & 3 & 0 & & \\
\hline
\end{tabular}


diretamente dentro do processo de negócio 'Gestão do Fluxo de Manufatura' no caso específico na Empresa 1.

No caso da Empresa 2, das 25 atividades logísticas teóricas inseridas nos processos de negócio, a sua função logística realiza 23 atividades, sendo somente 2 inexistentes:

- Dentro do processo de gestão da demanda, inexiste a atividade 11. 0 entrevistado não deu explicação para tal inexistência;

- No processo de gestão do retorno, inexiste a atividade 24. A inexistência desta atividade decorre da informalidade do próprio processo de negócio gestão do retorno e da consequente necessidade de seu maior desenvolvimento na Empresa 2.

\section{Discussões e considerações finais}

Este artigo oferece aos meios acadêmico e empresarial uma melhor compreensão sobre 0 aumento do escopo da logística a partir da SCM, em particular sobre a necessidade e a forma de envolvimento da função logística nos processos-chave de negócio através da proposição de atividades logísticas que podem ser executadas dentro de tais processos.

A partir da pesquisa de campo, pôde-se constatar a consistência das atividades logísticas propostas na realidade das empresas pesquisadas. Isso porque todos os entrevistados concordaram com a viabilidade de existência de tais atividades no meio empresarial e a maior parte dessas atividades existe nas empresas analisadas. Além disso, a maior parte das atividades é considerada como básica pelos entrevistados, o que é coerente com o fato de esta pesquisa não buscar por atividades novas ou inovadoras. Muitas das atividades logísticas aqui apresentadas são as tradicionais da logística e foram levantadas a partir de trabalhos específicos da literatura. No entanto, atualmente, tais atividades podem ser executadas dentro das esferas de processos de negócio, no sentido de a logística não ser mais uma função empresarial isolada, mas sim integrada a outras áreas e aos processos-chave de negócio da SCM. Sendo assim, não se buscou identificar se as atividades logísticas propostas eram novas ou não, mas sim verificar a consistência de sua implementação dentro dos processos de negócio.

Observou-se que a configuração do escopo da função logística na realidade empresarial depende fortemente das características internas de cada empresa. Portanto, a inexistência de atividades logísticas propostas é explicada por fatores internos a cada empresa. No caso da Empresa 1, duas das atividades (16 e 17) inexistem pela estruturação da área de fabricação de forma isolada à função logística; ao passo que a atividade 2 inexiste pela postura ética da empresa de não buscar informações sobre forças e fraquezas logísticas dos concorrentes; e a atividade 3 inexiste pela discordância do entrevistado sobre a formulação da redação da atividade (ele queria dar ênfase ao maior poder relativo do varejo no canal de distribuição de produtos alimentícios). No caso da Empresa 2, o menor tempo concedido para a entrevista inviabilizou apontar razões aprofundadas para a inexistência da atividade 11 , mas sugere-se que as implicações logísticas advindas da variabilidade da demanda não são tratadas pela empresa e/ou não se alcança a flexibilidade da logistica em tal empresa. Em relação à atividade 24 , no momento de realização da entrevista, o processo de retorno ocorria de modo informal na Empresa 2, pois apesar de existirem atividades de retorno gerenciadas pelo subprocesso "Distribuição", não havia um processo ou subprocesso específico para isso. Particularmente, o entrevistado sugeriu que, naquele momento, a empresa era falha em desenvolver opções de conduta para os produtos ou materiais retornados, como reciclagem, remanufatura ou uso por mercados secundários. Mas ele relatou a existência da prática de retirada das gôndolas dos varejistas dos produtos com data de vencimento prestes a expirar. Conforme ele, há uma tendência de a gestão de retorno da Empresa 2 ser mais desenvolvida no futuro.

Outra constatação muito importante, a partir do Quadro 13: muitos processos-chave de negócio da SCM estão dentro do escopo da função logística nas três empresas pesquisas. Assim, a função logística não só influencia os processos de negócio como também coordena e realiza muitos deles nessas empresas, a saber: CRM, Gestão do serviço ao cliente, Atendimento de pedidos, Gestão de retorno, Gestão do relacionamento com fornecedores, Gestão da demanda e Gestão do fluxo de manufatura.

Assim, de uma forma geral, a logística atualmente exerce suas atividades não mais com uma postura reativa e de forma isolada em sua área departamental ou funcional, em que somente recebe pedidos de trabalho e os atende. A logística passa a interferir, com uma postura proativa, também nas decisões estratégicas e táticas da empresa, dando suporte aos processos-chave de negócio e até realizando parcial ou integralmente os próprios processos de negócio de uma empresa. A logística continua recebendo pedidos de trabalho e os atendendo, mas também influencia nas questões de planejamento e execução dentro dos processos, por exemplo, disponibilizando informações logísticas a outras áreas ou ao grupo de gestão do processo.

A partir disso, confirma-se que o escopo da logística ultrapassou o nível funcional e vertical e 
alcançou também o nível horizontal dos processos de negócio. A atuação horizontal visa à melhoria na prestação do serviço ao cliente. Dado que Ballou (2001) classifica os elementos do serviço logístico conforme o momento em relação à transação (na pré-transação, na transação e na pós-transação), pode-se classificar as atividades logísticas propostas em termos de influência nessas três fases. Em particular, o serviço ao cliente na transação objetiva a realização completa da gestão e operacionalização dos ciclos dos pedidos. Nesse sentido, as atividades logísticas podem ocorrer na pré-transação e, assim, estarem presentes antes mesmo de o cliente colocar seu pedido à empresa, como é o caso das atividades logísticas implementadas nos processos de negócio CRM, Gestão do relacionamento com fornecedores, Gestão da demanda, Gestão do fluxo de manufatura (se a produção for "empurrada" para estoque) e Desenvolvimento e comercialização de produtos. Já outras atividades logísticas podem ocorrer na transação e, portanto, estarem presentes depois da colocação do pedido pelo cliente, como as atividades implementadas nos processos de Gestão do fluxo de manufatura (se a produção for "puxada" a partir de pedidos dos clientes), de Gestão do serviço ao cliente e atendimento de pedidos, visando operacionalizar os ciclos dos pedidos bem como evitar que falhas aconteçam no atendimento ao cliente. Outras atividades podem ocorrer na pós-transação, estando presentes depois que o cliente recebeu o produto e, por algum motivo (podendo ser de natureza ambiental), é necessário o retorno ou a devolução (de todo o produto, de seus materiais e/ou de suas embalagens), caso das atividades logísticas implementadas no processo de Gestão do retorno.

Com a SCM, a função logística ampliou seu escopo de atuação, ultrapassando a simples operacionalização do atendimento dos pedidos para incluir também a "gestão do pedido", enfatizando a importância da prestação eficiente e eficaz do serviço logístico. Conforme o entrevistado da Empresa 1, a gestão do pedido ocorre desde o momento em que o cliente faz o pedido até o seu atendimento, podendo incluir as avaliações dos motivos de devolução, quando for 0 caso. 0 entrevistado da Empresa 3 também deixou explícito que o processo de logística que a empresa realiza atualmente inclui também o serviço ao cliente por meio da "gestão do pedido". Mas do ponto de vista desta empresa, a gestão do pedido ocorre desde o momento em que o cliente fez o pedido, passando pelo momento em que o pedido foi entregue e termina quando o cliente faz o pagamento da fatura, consequentemente, quando a empresa recebe o dinheiro por esse pedido atendido (order-to-cash). Para realizar a gestão e a operacionalização efetivas dos ciclos dos pedidos, a função logística necessita estar presente nos processos-chave de negócio, realizando atividades que dão suporte aos processos e/ou áreas departamentais e visando a melhoria no atendimento dos pedidos dos clientes.

Diante de tudo o que foi exposto, durante os estudos de caso, observou-se que nas empresas pesquisadas o escopo da função logística, no contexto da SCM, foi ampliado para além do que discute a teoria. Tal situação resulta do fato de a SCM ser um conceito originado no ambiente empresarial e ter seu desenvolvimento fortemente vinculado a esse ambiente.

Como este artigo foi inicial no tema referente ao envolvimento da função logística nos processos-chave de negócio da SCM, foi inicial, pesquisas futuras devem utilizar outras teorias que se voltem à consideração da totalidade dos aspectos contextuais e específicos às organizações para aprofundar a discussão dos resultados por ele obtidos. Desse modo, pesquisas futuras devem usar a Teoria da Contingência, que não foi foco desta pesquisa, para complementar a discussão dos resultados. A Teoria da Contingência defende que não há uma única melhor forma de gestão que sirva para todas as situações, mas sim que a definição da estrutura e dos processos mais efetivos para certa organização é relativa e depende do contexto e das condições nos quais ela se insere. Ou seja, o planejamento, a organização e o controle de uma organização são efetivos se forem adaptados ao contexto e às circunstâncias particulares da organização em questão. Os fatores e as situações de contexto variam conforme o caso e mudam ao longo do tempo. Assim, essa abordagem é contrária aos paradigmas das "melhores práticas" e de "classe mundial" que defendem princípios aplicados universalmente (DRAZIN; VAN DE VEN, 1985; WANKE; CORREA; HIJJAR, 2010). Para Fabbe-Costes e Jahre (2008), mesmo não sendo uma teoria específica das áreas de logística e SCM, a Teoria da Contingência deve ser usada para melhorar o conhecimento nessas duas áreas e, assim, contribuir para a construção de suas teorias. Entretanto, Wanke, Correa e Hijjar (2010) expuseram que é ainda escassa a literatura sobre a SCM abordada conforme a Teoria da Contingência.

Além disso, pesquisas futuras devem desenvolver frameworks que orientem a análise e escolha das atividades logísticas pelas empresas, de forma a auxiliar a implementação dessas atividades dentro dos processos de negócio existentes na empresa. Para tanto, deve-se considerar a estratégia corporativa da empresa e a necessidade de alinhamento da contribuição de cada atividade logística a essa estratégia. Principalmente, devem ser considerados o impacto da atividade logística sobre os elementos 
do serviço logístico ofertado e seu alinhamento com a estratégia corporativa, a necessidade ou não de integração com outras áreas ou processos de negócio para a realização de cada atividade logística e a necessidade de cada atividade logística ter seu desempenho mensurado.

Quanto às limitações da pesquisa, durante as entrevistas, em função da restrição de tempo das empresas, não foi possível perguntar para os entrevistados sobre os motivos da atribuição de determinadas respostas sobre as atividades logísticas, o que reflete uma das limitações desse trabalho. Pesquisas futuras devem indagar sobre os "por quês" da classificação de cada atividade, complementando os resultados desta pesquisa.

Sobre a generalização dos resultados, Ellram (1996) afirma que estudos de caso múltiplos geram resultados mais generalizáveis do que estudo de caso únicos. A generalização propiciada pelos estudos de caso é mais qualitativa em sua natureza pois, para Yin (2001), a generalização é para proposições teóricas e não para populações ou universos. Assim, a generalização para o ambiente empresarial depende da elaboração de pesquisas que envolvam um número maior de empresas participantes.

Além disso, como esta pesquisa foi inicial no tema, não foi possível analisar a influência do porte das empresas sobre a consistência das atividades logísticas inseridas nos processos de negócio, evidenciando outra oportunidade para pesquisas futuras.

\section{Referências}

BALlOU, R. H. Gerenciamento da Cadeia de Suprimentos: Planejamento, Organização e Logística Empresarial. 4. ed. Porto Alegre: Bookman, 2001. 532 p.

BOLUMOLE, Y. A.; KNEMEYER, A. M; LAMBERT, D. M. The Customer Service Management Process. The International Journal of Logistics Management, v. 14, n. 2, 2003. http://dx.doi.org/10.1108/09574090310806576

BOLUMOLE, Y. A.; KNEMEYER, A. M; LAMBERT, D. M. The Customer Service Management Process. In: LAMBERT, D. M. Supply Chain Management: processes, partnerships, performance. 3rd ed. Supply Chain Management Institute, 2008. cap. 4.

BOWERSOX, D. J.; ClOSS, D J.; COOPER, M. B. Gestão logística de cadeias de suprimentos. Porto Alegre: Bookmam, 2006. 529 p.

BOWERSOX, D. J.; ClOSS, D J.; COOPER, M. B. Gestão da cadeia de suprimentos e logística. Rio de Janeiro: Elsevier, 2007. 442 p.

BOWERSOX, D. J.; CLOSS, D. J. Logística Empresarial: o processo de integração da cadeia de suprimento. São Paulo: Editora Atlas, 2001. 594 p.

CHRISTOPHER, M. Logística e Gerenciamento da Cadeia de Suprimentos: estratégias para a redução de custos e melhoria dos serviços. São Paulo: Pioneira, 1997.
CROXTON, K. L. The Order Fulfillment Process. The International Journal of Logistics Management, v. 14, n. 1, 2002.

CROXTON, K. L. The Order Fulfillment Process. In: LAMBERT, D. M. Supply Chain Management: processes, partnerships, performance. 3rd ed. Supply Chain Management Institute, 2008. cap. 6.

CROXTON, K. et al. The Supply Chain Management Process. International Journal of Logistics Management, v. 12, n. 2, 2001. http://dx.doi. org/10.1108/09574090110806271

CROXTON, K. L. et al. The Demand Management Process. The International Journal of Logistics Management, v. 13, n. 2, 2002. http://dx.doi. org/10.1108/09574090210806423

CROXTON, K. L. et al. The Demand Management Process. In: LAMBERT, D. M. Supply Chain Management: processes, partnerships, performance. 3rd ed. Supply Chain Management Institute, 2008. cap. 5.

DAVIS, B. R.; MENTZER, J. T. Logistics service driven loyalty: an exploratory study. Journal of Business Logistics, v. 27, n. 2, p. 53-73, 2006. http://dx.doi. org/10.1002/j.2158-1592.2006.tb00217.x

DONADEL, C. M. et al. Comparação do Modelo Supply Chain Operations Reference (SCOR) e o Modelo do Global Supply Chain Forum (GSCF). In: ENCONTRO NACIONAL DE ENGENHARIA DE PRODUÇÃO - ENEGEP, 27., 2007, Foz do lguaçu. Anais... Foz do lguaçu, 2007.

DRAZIN, R.; VAN DE VEN, A. H. Alternative forms of fit in contingency theory. Administrative Science Quaterly, v. 30, n. 4, 1985.

ELLRAM, L. M. The use of the case study method in logistics research. Journal of Business Logistics, v. 17, n. 2, 1996.

FABBE-COSTES, N.; JAHRE, M. Supply chain integration and performance: a review of the evidence. The International Journal of Logistics Management, v. 19, n. 2, 2008. http://dx.doi.org/10.1108/09574090810895933

FLEURY, P. F.; WANKE, P. Logística no Brasil. In: FIGUEIREDO, K. F.; FLEURY, P. F.; WANKE, P. (Org.). Logística e Gerenciamento da Cadeia de Suprimentos: planejamento do fluxo de produtos e dos recursos. São Paulo: Atlas, 2003. cap. 2.

GODSELL, J.; JOHNSON, M.; VAN HOEK, R. How do we know what we know? A review of methods use in operations and supply chain management research. In: INTERNATIONAL ANNUAL EUROMA CONFERENCE MANAGING OPERATIONS IN SERVICE ECONOMIES, 17., 2010, Porto. Proceedings... Porto, 2010.

GOLDSBY, T. J.; GARCÍA-DASTUGUE, S. J. The Manufacturing Flow Management Process. The International Journal of Logistics Management, v. 14, n. 2, 2003. http://dx.doi. org/10.1108/09574090310806585

GOLDSBY, T. J.; GARCíA-DASTUGUE, S. J. The Manufacturing Flow Management Process. In: LAMBERT, D. M. Supply Chain Management: processes, partnerships, performance. 3rd ed. Supply Chain Management Institute, 2008. cap. 7.

HUTT, M. D.; SPEH, J. W. Supply Chain Management. In: HUTT, M. D. Business marketing management: an strategic view of industrial and organizational markets. 7th ed. Harcourt College Publishers, 2001. cap. 6, p. 139-170.

KAUFFMAN, R. G. Supply Management: What's in a Name? Or, Do We Know Who We Are? The Journal of Supply 
Chain Management, v. 38, n. 4, p. 46-50, Nov 2002. http://dx.doi.org/10.1111/j.1745-493X.2002.tb00142.x

LAMBERT, D. M. The eight essential supply chain management processes. Supply Chain Management Review, v. 8, n. 6, Sept 2004.

LAMBERT, D. M. Supply Chain Management. In: LAMBERT, D. M. Supply Chain Management: processes, partnerships, performance. 3rd ed. Supply Chain Management Institute, 2008a. cap. 1.

LAMBERT, D. M. The Customer Relationship Management Process. In: LAMBERT, D. M. Supply Chain Management: processes, partnerships, performance. 3rd ed. Supply Chain Management Institute, 2008b. cap. 2.

LAMBERT, D. M. The Supplier Relationship Management Process. In: LAMBERT, D. M. Supply Chain Management: processes, partnerships, performance. 3rd ed. Supply Chain Management Institute, 2008c. cap. 3.

LAMBERT, D. M; GARCIA-DASTUGUE, S. J.; CROXTON, K. L. An evaluation of process-oriented supply chain management frameworks. Journal of Business Logistics, v. 26, n. 1, 2005. http://dx.doi.org/10.1002/j.2158-1592.2005. tb00193.x

LAMBERT, D. M.; GARCÍA-DASTUGUE, S. J.; CROXTON, K. $\mathrm{L}$. The role of logistics managers in the cross-functional implementation of supply chain management. Journal of Business Logistics, v. 29, n. 1, 2008. http://dx.doi. org/10.1002/j.2158-1592.2008.tb00071.x

MANUJ, 1.; MENTZER, J. T. Global supply chain risk management strategies. International Journal of Physical Distribution \& Logistics Management, v. 38, n. 3, 2008. http://dx.doi.org/10.1108/09600030810866986

MARCHESINI, M. M. P. As capacitações e os recursos logísticos para a prática do Supply Chain Management (SCM). 2005. Dissertação (Mestrado em Engenharia de Produção)-Universidade Federal de São Carlos, São Carlos, 2005.

MENTZER, J. T. et al. Defining Supply Chain Management. Journal of Business Logistics, v. 22, n. 2, p. 1-25, 2001. http://dx.doi.org/10.1002/j.2158-1592.2001.tb00001.x

MIGUEL, P. A. C. Estudo de caso na engenharia de produção: estruturação e recomendações para sua condução. Revista Produção, v. 17, n. 1, p. 216-229, 2007. http:// dx.doi.org/10.1590/S0103-65132007000100015
MOLLENKOPF, D.; RUSSO, 1.; FRANKEL, R. The returns management process in supply chain strategy. International Journal of Physical Distribution \& Logistics Management, v. 376, n. 7, 2007.

ROGERS, D. S. et al. The Returns Management Process. International Journal of Logistics Management, v. 13, n. 2, 2002. http://dx.doi. org/10.1108/09574090210806397

ROGERS, D. S. et al. The Returns Management Process. In: LAMBERT, D. M. Supply Chain Management: processes, partnerships, performance. 3rd ed. Supply Chain Management Institute, 2008. cap. 9.

ROGERS, D. S.; LAMBERT, D. M.; KNEMEYER, A. M. The Product Development and Commercialization Process. The International Journal of Logistics Management, v. 15, n. 1, 2004. http://dx.doi. org/10.1108/09574090410700220

ROGERS, D. S.; LAMBERT, D. M.; KNEMEYER, A. M. The Product Development and Commercialization Process. In: LAMBERT, D. M. Supply Chain Management: processes, partnerships, performance. 3rd ed. Supply Chain Management Institute, 2008. cap. 8.

STANK, T.; DAVIS, B.; FUGATE, B. A Strategic Framework for Supply Chain Oriented Logistics. Journal of Business Logistics, v.26, n.2, p.27-46, 2005. http://dx.doi. org/10.1002/j.2158-1592.2005.tb00204.x

THOMAS, R. W.; ESPER, T. L. Exploring relational asymmetry in supply chains: the retailer's perspective. International Journal of Physical Distribution \& Logistics Management, v. 40, n. 6, 2010. http://dx.doi. org/10.1108/09600031011062209

WANKE, P. F.; CORREA, H. L.; HIJJAR, M. F. Establishing the relationship between logistics complexity and supply chain objectives and decision areas in large companies operating in Brazil. Journal of Operations and Supply Chain Management, v. 3, n. 1, 2010.

WANKE, P. Logística, Gerenciamento de Cadeias de Suprimentos e Organização do Fluxo de Produtos. In: FIGUEIRED0, K. F.; FLEURY, P. F.; WANKE, P. (Org.). Logística e Gerenciamento da Cadeia de Suprimentos: planejamento do fluxo de produtos e dos recursos. São Paulo: Atlas, 2003. cap. 1.

YIN, R. K. Estudo de Caso: planejamento e métodos. 2. ed. Porto Alegre: Bookman, 2001. 205 p.

\begin{abstract}
According to Supply Chain Management (SCM), the logistic function expands its scope within the company to exert or support the management and operation of different key business processes. The benefits generated by the involvement of the logistic function in such processes of SCM have been widely discussed in the literature, but the logistics activities that must be executed in each of these processes to achieve such benefits have not been identified. The aim of this paper was to propose logistics activities necessary for efficient and effective operation of the different key business processes of SCM. This article is theoretical-conceptual and exploratory; it adopts a qualitative research approach using a semi-structured questionnaire in multiple case studies and personal interviews. The consistency of logistics activities proposed in the researched companies was found, and the existence of these activities depended heavily on the internal characteristics of each company. It was confirmed that the logistics function performs activities that are no longer reactive or isolated to its own department or primary function; instead, it assumes a proactive attitude within business processes.
\end{abstract}

\title{
Proposal of logistic activities in Supply Chain Management
}

\section{Keywords}

Supply Chain Management (SCM). Key business processes. Scope of logistic management. Logistic activities. 